\title{
RECOMBINED GRAFTS OF BONE AND MARROW
}

\section{The Beneficial Effect upon Osteogenesis of Impregnating Xenograft (Heterograft) Bone with Autologous Red Marrow}

\author{
R. Salama, Tel-Aviv, Israel, R. Geoffrey Burwell and I. R. Dickson, \\ LONDON, ENGLAND
}

From the Institute of Orthopaedics, London

The beneficial effect upon osteogenesis of impregnating allograft (homograft) bone with autologous red marrow has been reported in several publications (Burwell 1964, 1966; Matthes, Gibel, Wildner and Marx 1968; Boyne 1970; Nade 1970). This paper reports a study of the fate of sheep and calf cancellous bone grafts impregnated with autologous red marrow and implanted into rats as composite xenograft-autografts. There is one previous publication relating to the effect upon osteogenesis of impregnating xenograft bone (Kiel bone) with red marrow (Hollmann, Plenk and Wilfert 1971).

SHEEP

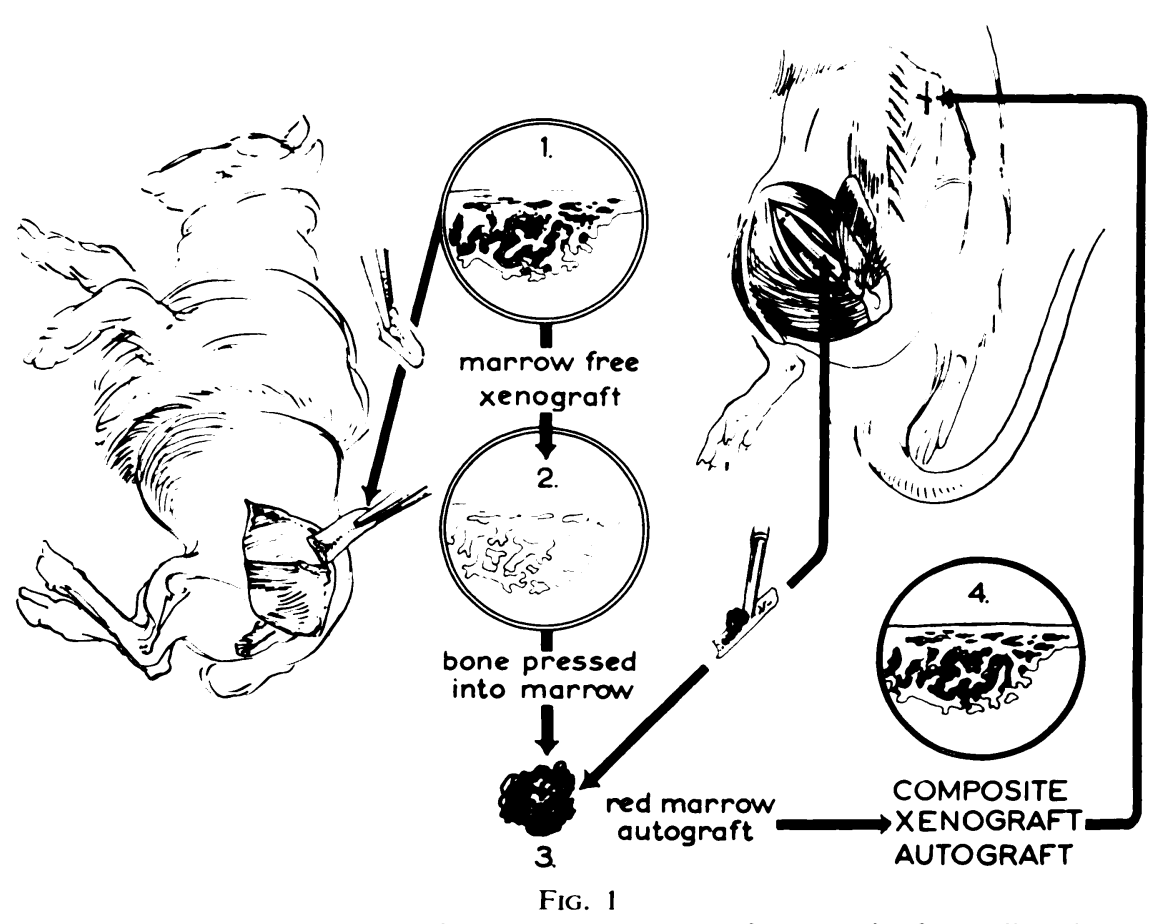

The method of preparation of a fresh composite xenograft-autograft of cancellous bone.

\section{MATERIALS AND METHODS}

The experimental design used (Fig. 1) was like that employed before for evaluating the effect of impregnating fresh and treated allografts of cancellous bone with autologous red marrow (Burwell 1964, 1966).

THE DONOR BONE AND METHODS OF TREATMENT

Sheep bone-Bone was removed under sterile conditions from both ilia of two ewes aged between five and eight years. The bone, except that required for preparation by the Kiel 
and Oswestry methods, was immediately cut into fragments about $3 \times 3 \times 1$ millimetres and the marrow washed out with a jet of pyrogen-free distilled sterile water at 4 degrees Celsius and at a pressure of $103 \mathrm{kNm}^{2}$ (15 pounds/square inch). The fragments were then placed in sterile glass containers.

Different samples were treated as follows.

Frozen sheep bone-This bone was stored directly at -20 degrees Celsius in a commercial deep-freeze until used in the surgical procedure.

Freeze-dried sheep bone-The fragments were freeze-dried in an Edwards high vacuum machine for two days before storage at room temperature.

Decalcified frozen sheep bone-The fragments were placed in $0.6 \mathrm{~N}$ hydrochloric acid at 4 degrees Celsius and allowed to decalcify for two hours in a shaking water-bath. The acid was then removed and the decalcified bone washed twice in phosphate buffer at $\mathrm{pH}=7.4$ before storage at -20 degrees Celsius.

Decalcified freeze-dried sheep bone-The fragments were decalcified in a similar way and then freeze-dried before storage at room temperature.

Kiel sheep bone-Segments of whole ilium placed in sterile glass containers were transported by air in a box containing dry ice to Melsungen, West Germany, for preparation. At the factory the bone fragments were washed, cut, processed and sterilised and returned by air mail at ambient temperature. Portions measuring $10 \times 10 \times 1$ millimetres stored at room temperature were chosen for the operations, each piece being broken into four fragments for use as separate grafts.

Oswestry sheep bone-Segments of whole ilium were transported by surface mail at ambient temperature to the Robert Jones and Agnes Hunt Orthopaedic Hospital for preparation according to the method described by Kershaw (1963). After deproteinisation, fragments measuring about $3 \times 3 \times 3$ millimetres were stored at room temperature.

Calf bone-Calf bone was removed under sterile conditions from both ilia of a calf eight weeks old. After placing the fragments in sterile glass containers, the following two types of bone-graft material were prepared.

Kiel calf bone-This was prepared at Melsungen as described above for sheep bone. Oswestry calf bone-This was also prepared as for sheep bone.

SURGICAL PROCEDURE: THE PREPARATION AND IMPLANTATION OF THE COMPOSITE XENOGRAFT-AUTOGRAFTS

The 249 rats used in the study were male and female Wistar rats of 200-400 grammes weight. The method of preparation and insertion of the composite grafts and the control grafts without autologous red marrow was like that previously described for composite allograft-autografts (Burwell 1964), the red marrow being procured from the femoral shaft of the recipient rat (Fig. 1). The composite and the control grafts of each type were inserted into each of thirty rats to allow groups of ten to be killed two, six or twelve weeks later. In the case of the Oswestry sheep bone grafts, only five rats were available for the twelve-week group; in this group, four grafts, two composite and two control, were inserted into separate pockets in each paravertebral muscle, the marrow having been procured from each femur. Both the composite and the control grafts were removed for histological examination and quantitation of new bone formation two, six and twelve weeks after implantation.

\section{PROCESSING FOR HISTOLOGICAL EXAMINATION}

After fixation, the tissues were dehydrated in alcohol solutions, cleared in xylene and embedded in paraffin wax. Serial sections $5 \mu$ thick were cut through the whole of each block. The sections were mounted on glass slides so that two consecutive sections from each of ten sections (50 $\mu$ thickness) of the whole block were available for each graft. The sections were then stained by haematoxylin, eosin and alcian blue (Sayers 1972) and mounted in DPX.

VOL. 55 B, NO. 2, MAY 1973 
METHOD OF QUANTITATION

The histological quantitation of the material was undertaken by one of us (R. S.) who did not know which type of composite graft he was examining. The proportion of new bone to grafted bone was scored for one section every $50 \mu$ for the whole of the graft, using the arbitrary scale described by Burwell in 1966, namely: $0=$ no new bone; $1=$ about 10 per cent; $2=$ about 25 per cent; $3=$ about 50 per cent; and $4=$ about 100 per cent new bone. By dividing the aggregate score for each graft by the number of sections examined, a mean score of new bone to grafted bone was calculated (Nade 1969).

\section{IMMUNOLOGICAL STUDIES}

Some of the rats were bled by transverse section of the tail distally before and at intervals after the surgical procedure. The serum was examined for cytotoxic humoral antibodies against sheep white blood cells using a fluorochromatic cytotoxic test (Elves 1970). The results of this and other immunological studies of bone xenografts will be reported elsewhere (Elves and Salama 1972).

\section{RADIOLOGICAL STUDIES}

Specimens of sheep and calf cancellous bone were prepared in different ways and radiographed on "Kodaline" film at 25 kilovolts to compare the size of the intertrabecular spaces.

\section{BIOCHEMICAL STUDIES}

After the implantations had been completed some of the donor bone was used for certain biochemical estimations. Each sample was initially dried for twelve hours at 110 degrees Celsius in an oven and its weight determined before being examined for collagen, hexuronic acid, calcium and mineral. This aspect of the work, presented here as a preliminary study, was undertaken by one of the writers (I. R. D.).

Collagen-These samples were hydrolysed in $6 \mathrm{~N} \mathrm{HCl}$ at 100 degrees Celsius for twenty-four hours. The hydrolysates were evaporated to dryness in a vacuum desiccator containing potassium hydroxide pellets and phosphorus pentoxide. Hydroxyproline was estimated by the method of Woessner (1961). The percentage of collagen in each sample was assessed by multiplying the percentage of hydroxyproline by a factor of $7 \cdot 1$ (Eastoe 1955).

Hexuronic acid-This was determined by the method of Bitter and Muir (1962) using glucuronolactone standards, on samples which had been decalcified with $0.6 \mathrm{~N} \mathrm{HCl}$ and treated with papain by the method of Antonopoulos, Gardell, Szirmai and De Tyssonsk (1964). Calcium-The samples were agitated in $0.6 \mathrm{~N} \mathrm{HCl}$ at 4 degrees Celsius for twelve hours and then centrifuged at 1,000 " $g$ " for 10 minutes. Calcium was estimated in the supernatant solution using a "Unicam" SP90 atomic absorption spectrometer. The percentage of mineral in each sample was assessed by multiplying the percentage of calcium by a factor of 2.5 , based on the formula of hydroxyapatite as $\mathrm{Ca}_{10}\left(\mathrm{PO}_{4}\right)_{6}(\mathrm{OH})_{2}$.

\section{OBSERVATIONS AND RESULTS}

\section{HISTOLOGICAL OBSERVATIONS}

Frozen, freeze-dried and decalcified sheep bone with marrow (Figs. 2 and 4)-At two weeks occasional osteocytic nuclei were stained with haematoxylin. Osteoclasts were seen upon the surfaces of the frozen and the freeze-dried grafts but not the decalcified grafts. New bone of woven type was present in many of the intertrabecular spaces or upon the trabeculae of the grafted bone, and cartilage formation was observed in the decalcified grafts. Healthy-looking osteoblasts were present on the surfaces of this new bone and its osteocytes appeared normal. Those intertrabecular spaces which did not show woven bone contained a richly cellular tissue 
of small round cells, eosinophils, occasional mature plasma cells (hereafter simply termed plasma cells), mast cells, and particularly in the freeze-dried and decalcified grafts, cells with round, oval or spindle-shaped nuclei with pale chromatin and prominent nucleoli.

At six or twelve weeks none of the osteocytic nuclei of the grafted bone were stained

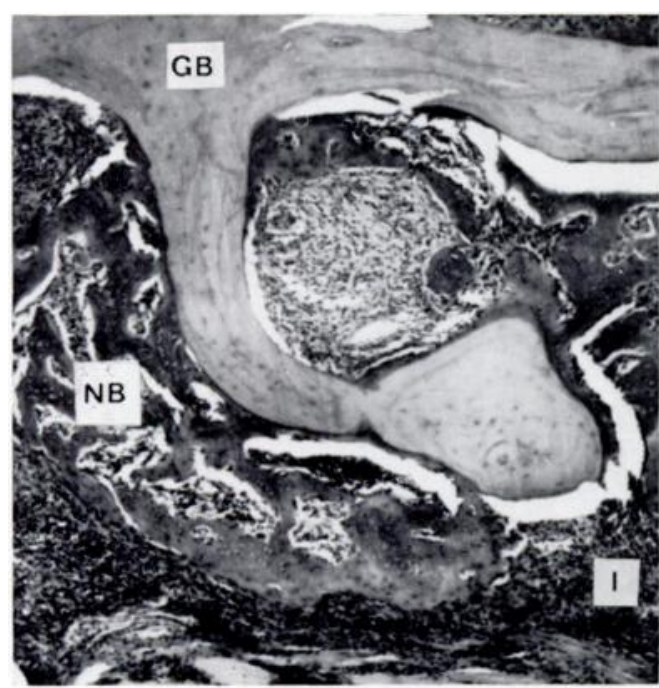

Fig. 2

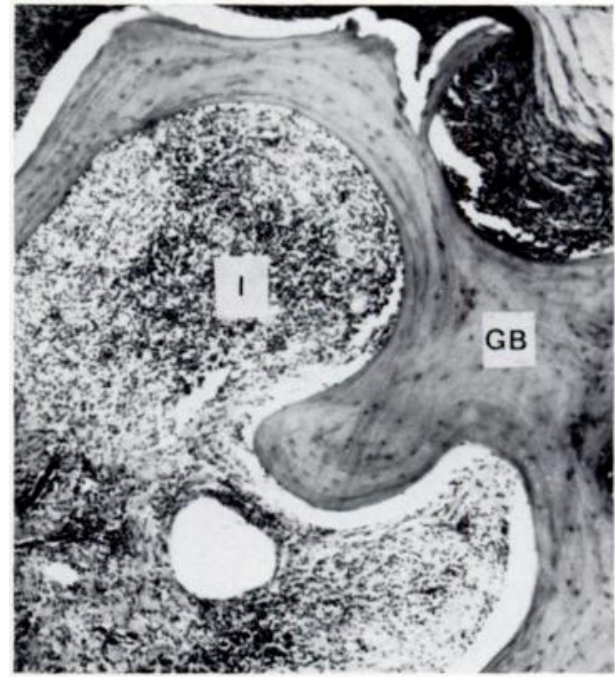

FIG. 3

Frozen ( -20 degrees Celsius) sheep bone xenografts after two weeks in muscle. Figure 2-Bone impregnated with fresh autologous red marrow. Note the formation of new woven bone. Figure 3-Bone not impregnated with fresh marrow. Note the absence of new bone. $\mathrm{GB}=$ grafted bone; $\mathrm{NB}=$ new bone; $\mathrm{I}=$ inflammatory infiltration. (Haematoxylin, eosin and alcian blue, $\times 50$.)

with haematoxylin. New bone of lamellar but also of woven type was seen which tended, with the grafted bone, to form irregular ossicles containing haemopoietic marrow. There was little evidence of remodelling of the grafted bone. Those intertrabecular spaces which did not contain living bone contained either a loose fibrous connective tissue with scattered plasma cells, eosinophils and small round cells (the latter aggregated in places as lymphoid follicles), or adipose tissue sparsely infiltrated with eosinophils, small round cells and occasional plasma cells. Haemopoietic marrow was observed in association with the new bone formation. The grafts were surrounded by a fibrous connective tissue.

Frozen, freeze-dried and decalcified sheep bone without marrow (Figs. 3 and 5)-At two weeks the osteocytic nuclei of the grafted bone were either unstained with haematoxylin or were pyknotic. A few osteoclasts were present on the surfaces of the frozen and the freeze-dried grafts but not the decalcified grafts. No new bone formation was observed in any of the grafts, but osteoclasts were observed in all the grafts after six or twelve weeks. At two weeks the intertrabecular spaces contained a loose, or richly cellular, vascularised tissue which included plasma cells, eosinophils and small round cells; the latter were aggregated in places as lymphoid follicles; and plasma cells were frequently observed in gatherings (Fig. 6).

At six weeks, but particularly at twelve weeks, the intertrabecular spaces contained adipose tissue or a loose fibrous connective tissue with plasma cells (in places as gatherings), some eosinophils, occasional mast cells, and in some grafts, haemosiderin-containing macrophages. The grafts were surrounded by a fibrous capsule.

Kiel and Oswestry sheep and calf bone with marrow (Figs. 7 and 9)-At two weeks the osteocytic nuclei of the grafted Kiel bone were not stained with haematoxylin. The grafted Oswestry bone was evident as an eosinophilic amorphous material in which occasional osteocytic lacunae were evident. Osteoclasts were seen on the surfaces of the grafted bone, the trabeculae 
of which were thicker and the intertrabecular spaces smaller than the calf bone. At two weeks most of the grafts showed new bone formation and cartilage formation was seen in some of the sheep Oswestry grafts. Those intertrabecular spaces which did not contain new

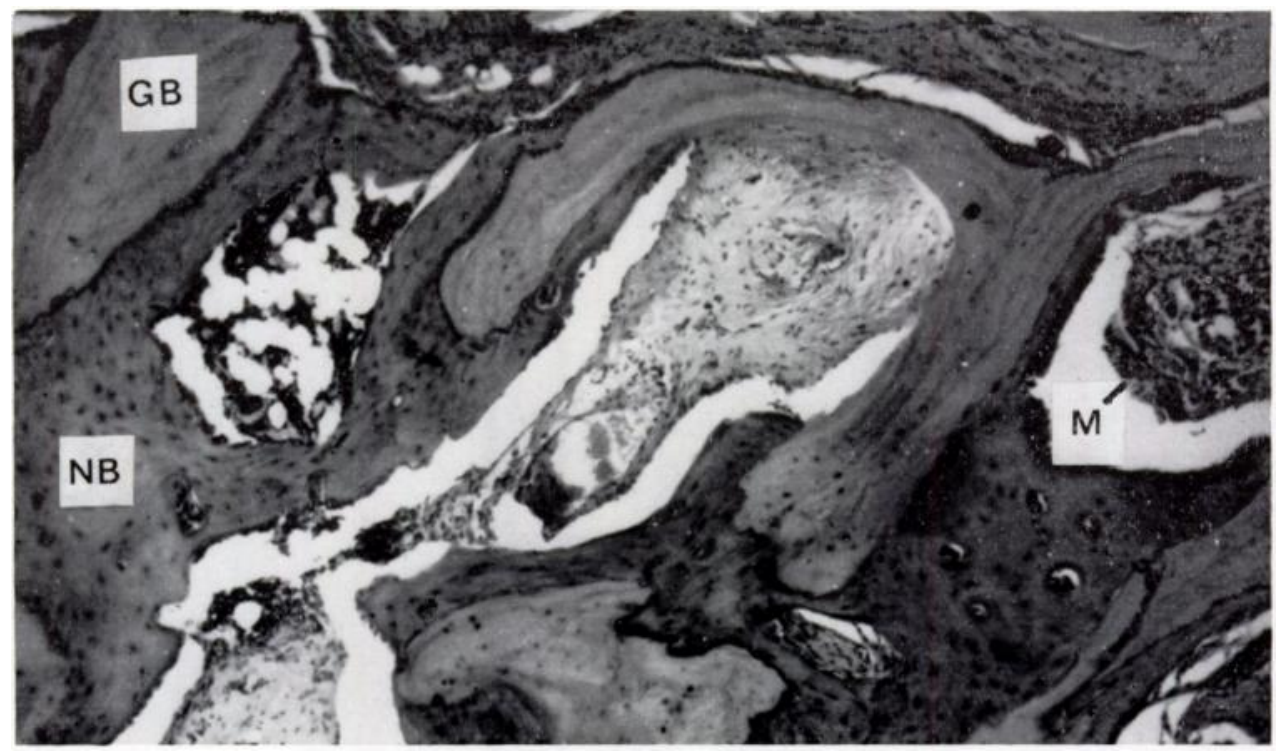

FIG. 4

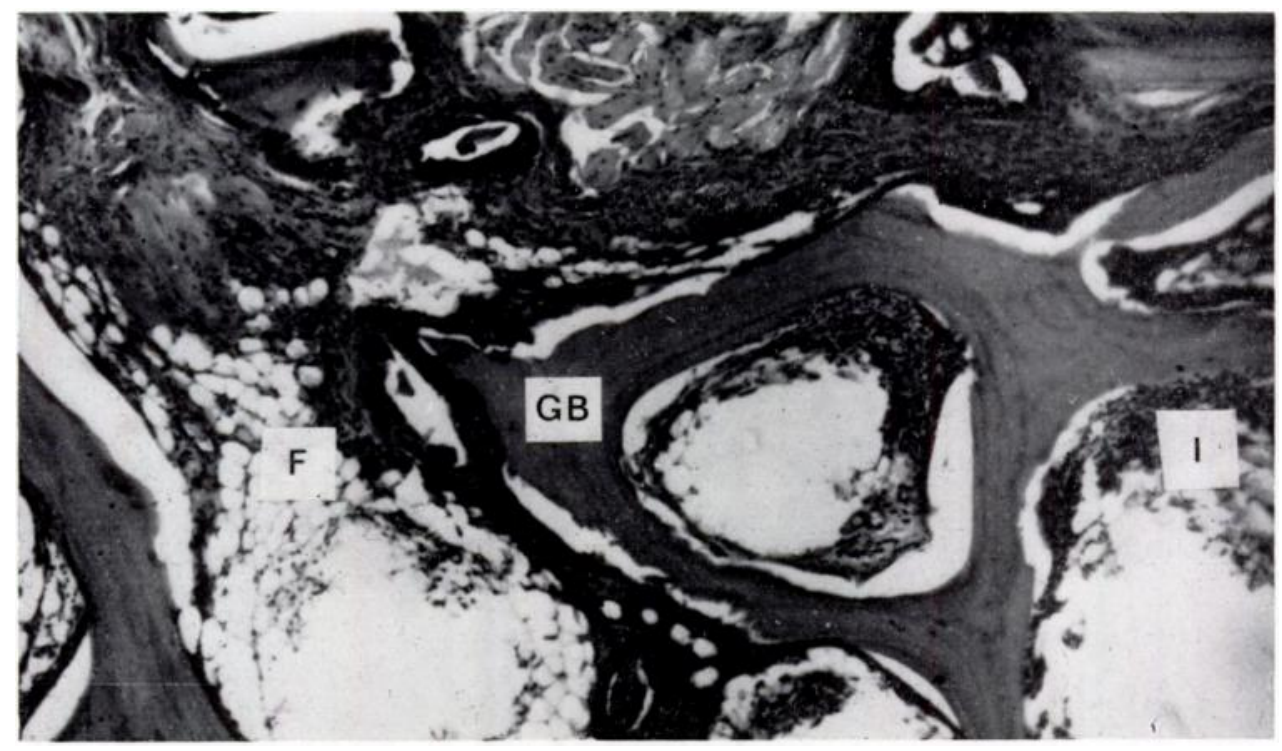

FIG. 5

Freeze-dried sheep bone xenografts after twelve weeks in muscle. Figure 4-Bone impregnated with fresh autologous red marrow. Note the formation of new lamellar bone. Figure 5-Bone not impregnated with fresh marrow. Note the absence of new bone. $M=$ marrow; $F=$ fat. (Haematoxylin, eosin and alcian blue, $\times 60$.)

bone showed either a loose fibrous connective tissue infiltrated, particularly centrally in the spaces, with small round cells, eosinophils, occasional plasma cells and giant cells, or a rich cellular tissue of spindle-shaped cells, small round cells, eosinophils and cells with round or oval nuclei, pale chromatin and prominent nucleoli. 
At six and twelve weeks the new bone was of lamellar type and associated with haemopoietic marrow containing megakaryocytes but with little or no remodelling of the

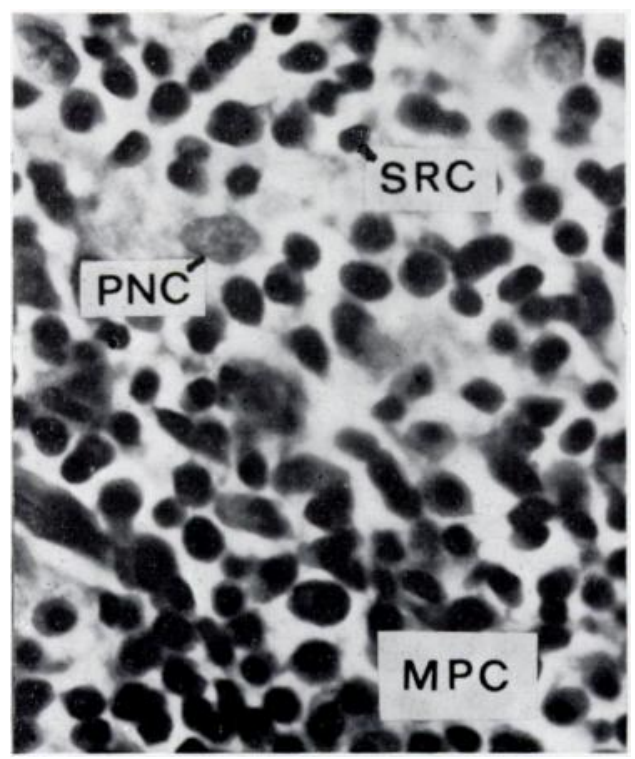

Fig. 6

An intertrabecular space of decalcified freezedried bone xenograft implanted without marrow after two weeks in muscle. Note the presence of mature plasma cells (MPC), small round cells (SRC) and cells with round or oval nuclei, pale chromatin and prominent nucleoli (PNC). (Haematoxylin, eosin and alcian blue, $\times 590$.)

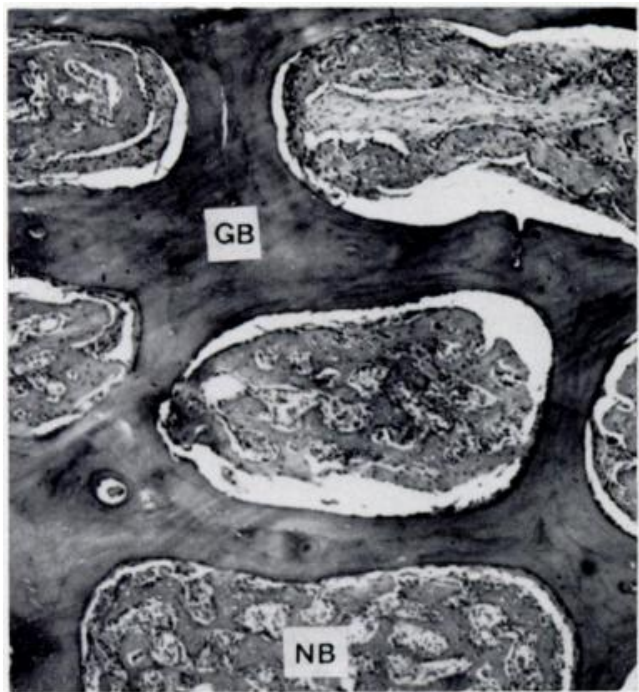

Fig. 7

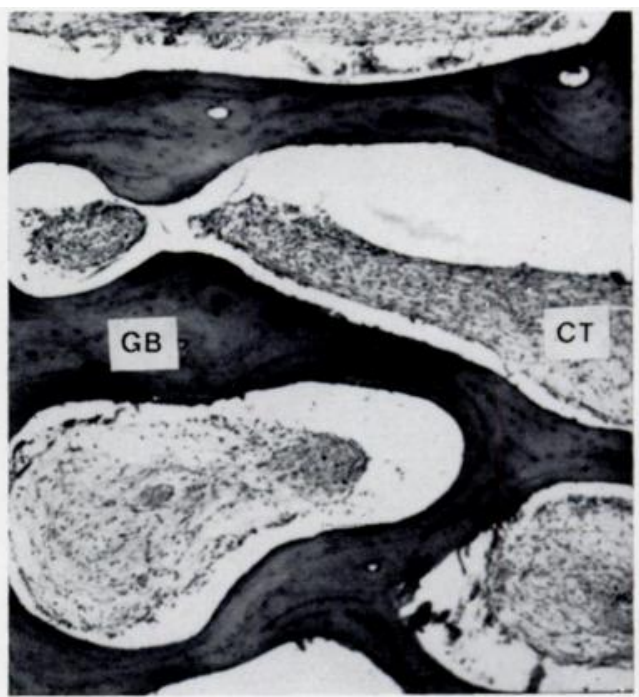

FIG. 8

Kiel calf bone xenografts removed after two weeks in muscle. Figure 7-Bone impregnated with fresh autologous red marrow. Note the formation of new woven bone. Figure 8-Bone not impregnated with fresh marrow. Note the absence of new bone. $C T=$ young connective tissue lightly infiltrated with small round cells and occasional mature plasma cells. (Haematoxylin, eosin and alcian blue, $\times 50$.)

grafted bone. The intertrabecular spaces contained a fibrous connective tissue infiltrated either with small round cells, eosinophils and rarely plasma cells, or particularly at twelve weeks, adipose tissue. The grafts were surrounded by a fibrous capsule. 
Kiel and Oswestry sheep and calf bone without marrow (Figs. 8 and 10)-The osteocytic nuclei were not stained with haematoxylin. Osteoclasts were observed on the surfaces of the grafted bone. There was no evidence of new bone formation except in one graft of Kiel calf bone

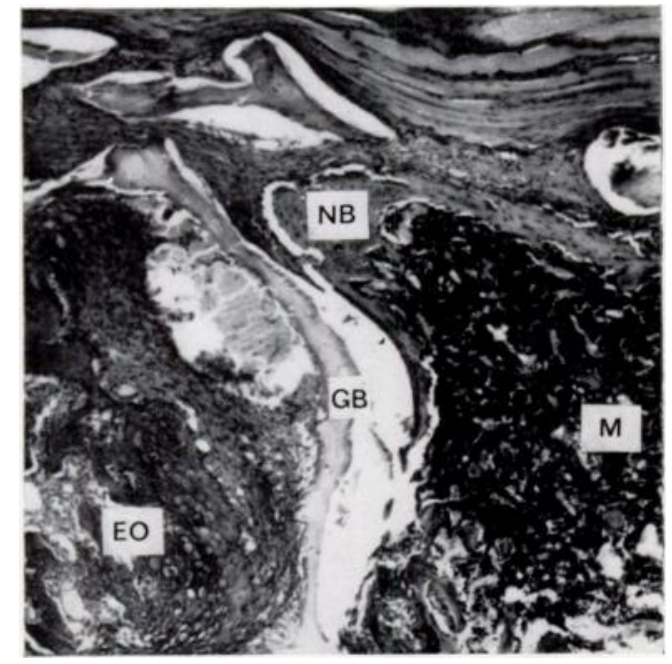

FIG. 9

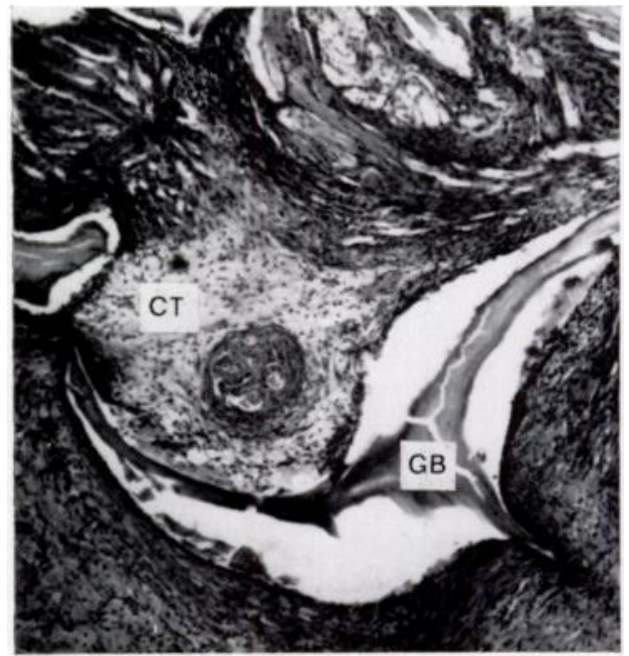

FIG. 10

Oswestry calf bone xenografts removed after six weeks in muscle. Figure 9-Bone impregnated with fresh autologous red marrow. Note the tendency of the impregnated graft to form a marrow-containing ossicle with endochondral ossification (EO). Figure 10-Bone not impregnated with fresh marrow. Note the inflammatory infiltration around the unimpregnated implant. (Haematoxylin, eosin and alcian blue, $\times 50$.)

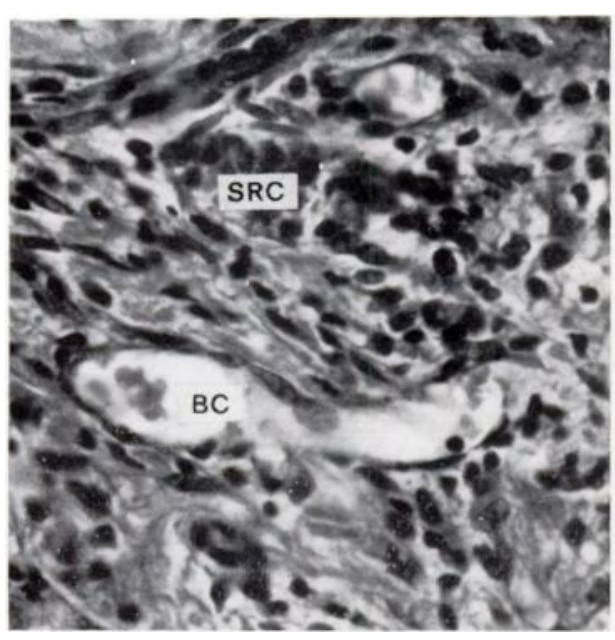

Fig. 11

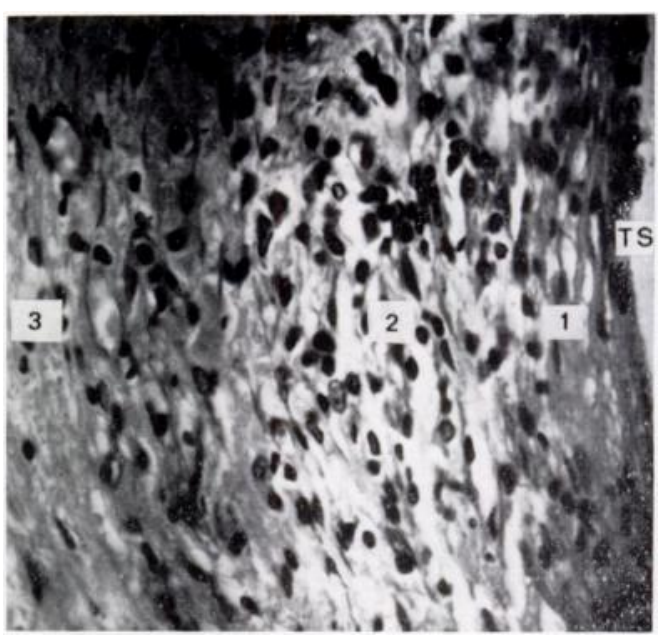

FIG. 12

Figure 11-An intertrabecular space of sheep Kiel bone xenograft implanted without marrow after two weeks in muscle. Note the loose connective tissue infiltrated with small round cells. $\mathrm{BC}=$ blood capillary. (Haematoxylin, eosin and alcian blue, $\times 400$.) Figure $12-$ An intertrabecular space (TS) of a sheep Oswestry bone xenograft implanted without marrow after two weeks in muscle. Note the condensation of tissue lying upon the trabecula (1), next a loose connective tissue lightly infiltrated with small round cells (2), and then young fibrous tissue (3). (Haematoxylin, eosin and alcian blue, $\because 400$.)

removed at twelve weeks. At two weeks the intertrabecular spaces contained a loose connective tissue, lightly or moderately infiltrated with small round cells and occasional eosinophils (Figs. 11 and 12). After six and twelve weeks a similar loose connective tissue was evident 


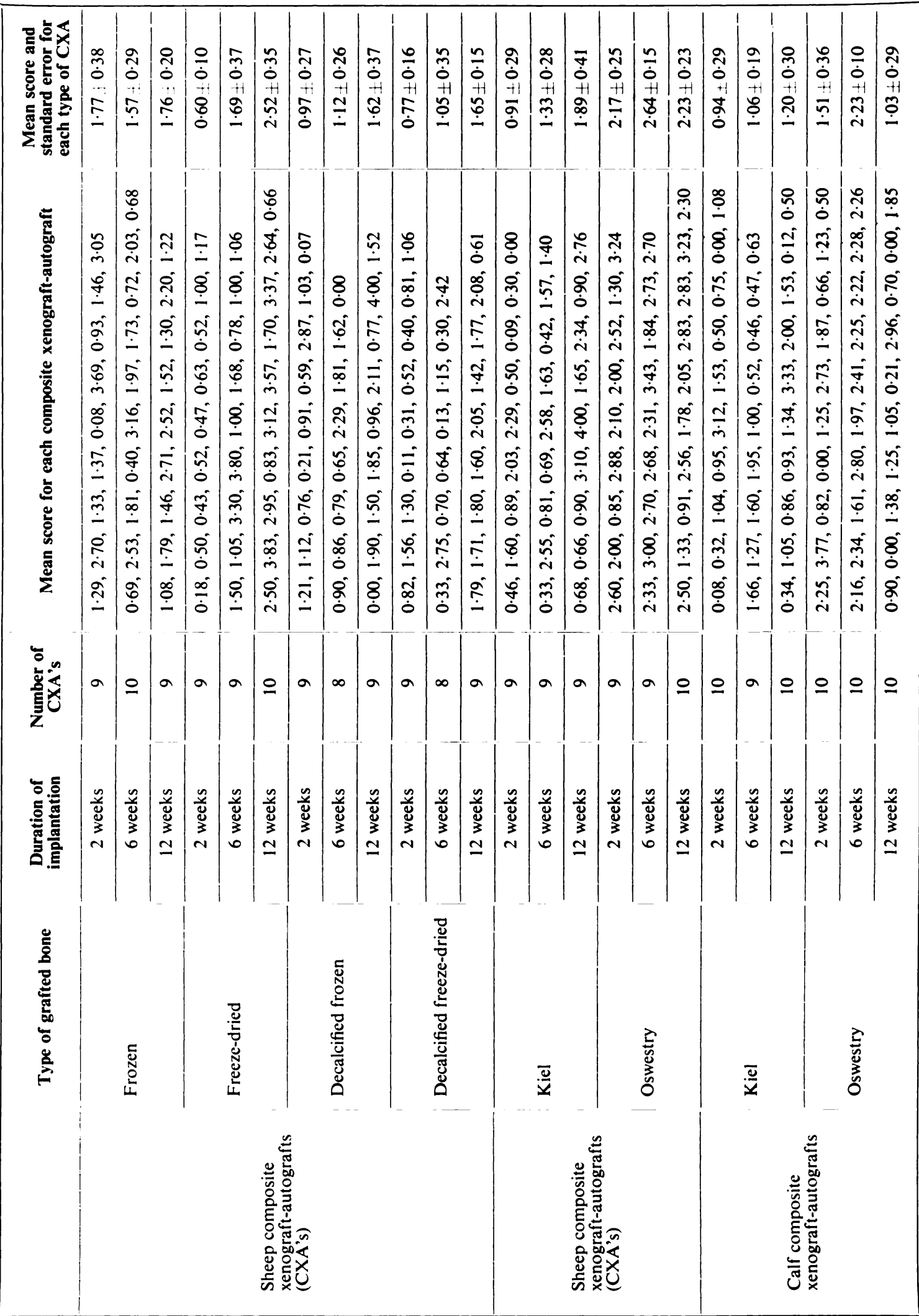

VOL. 55 B, NO. 2, MAY 1973 
in some spaces, in which plasma cells were seen. In other spaces adipose tissue was present which tended to lie centrally and be separated from the trabeculae of the grafted bone by loose fibrous tissue.
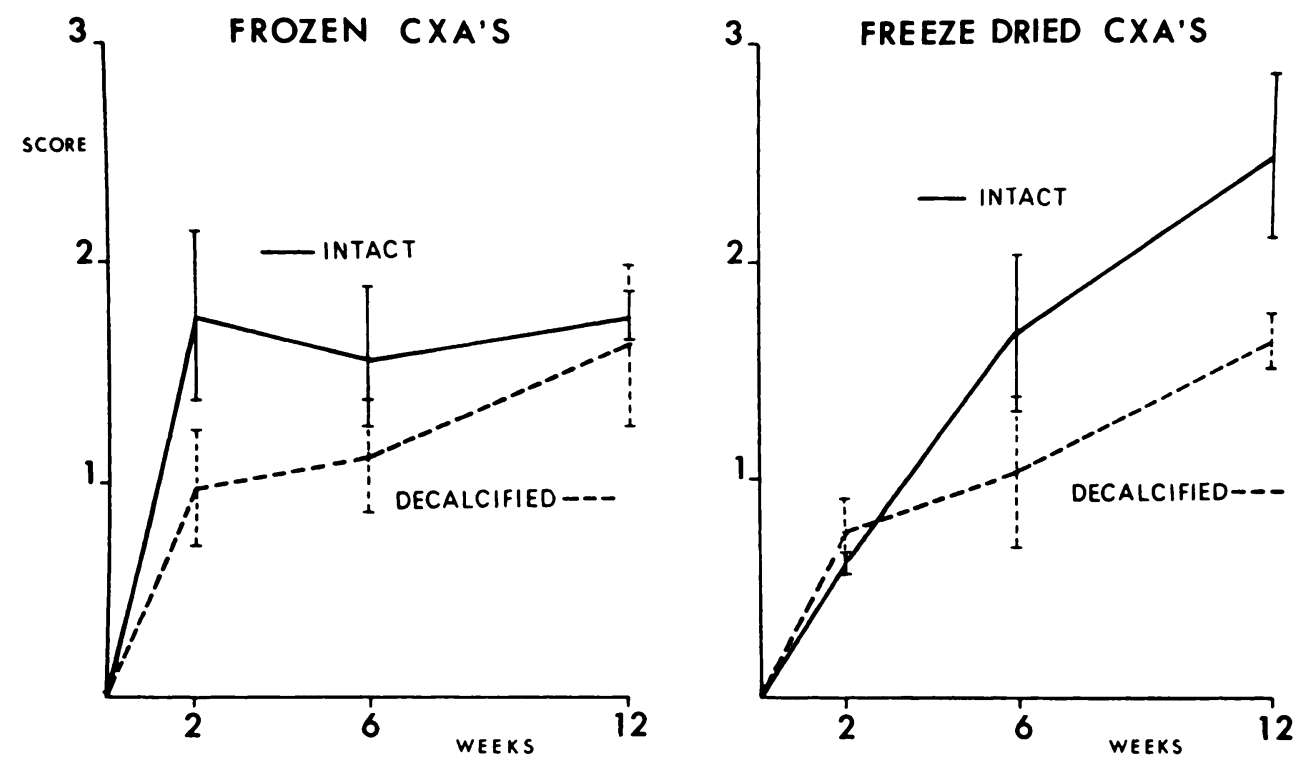

Fig. 13

Graphs to show the mean scores of new bone/grafted bone in intact and decalcified composite grafts prepared from frozen and freeze-dried sheep bone and removed two, six and twelve weeks after implantation in 109 rats (see text).
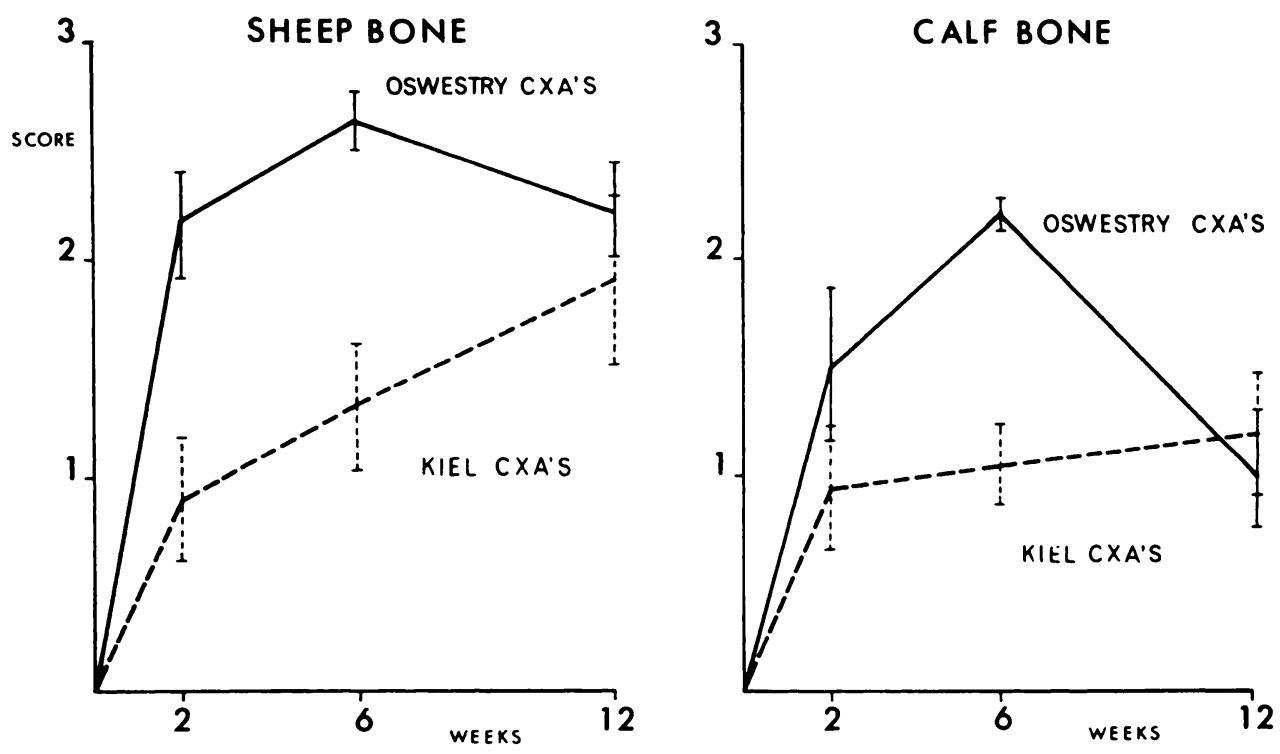

FIG. 14

Graphs to show the mean scores of new bone/grafted bone in Oswestry and Kiel composite grafts prepared from sheep and calf bone and removed two, six and twelve weeks after implantation in 114 rats (see text).

RESULTS OF THE QUANTITATION

The scores of the proportion of new bone to grafted bone in each of the various composite xenograft-autografts is shown in Table I. 
Comparison of the frozen with the freeze-dried composite xenograft-autografts (CXA's) - In Figure 13 are plotted the mean scores, and the standard errors of the means, for the frozen and freeze-dried CXA's removed two, six and twelve weeks after implantation. The results are plotted separately for the intact (untreated) and the decalcified bone.

A comparison of the intact frozen CXA's with the intact freeze-dried CXA's showed that at two weeks the former produced significantly more new bone than the latter $(0.01<P<0.001)$.

A comparison of the decalcified frozen CXA's with the decalcified freeze-dried CXA's did not show any difference in new bone formation at any of the time intervals studied.

When the intact CXA's (frozen and freeze-dried) were compared respectively with the decalcified CXA's for each time interval, there was no significant difference in new bone formation by the frozen and freeze-dried grafts except for the freeze-dried CXA's (intact and decalcified) removed at twelve weeks $(0.02<\mathrm{P}<0.05)$.

The decalcified CXA's (frozen and freeze-dried together) formed significantly less new bone $(1 \cdot 20 \pm 0 \cdot 12)$ than did the intact undecalcified CXA's (frozen and freeze-dried together) $(1 \cdot 66 \pm 0 \cdot 14)(0.01<\mathrm{P}<0.02)$.

Comparison of Kiel with Oswestry (CXA's) from donor bone of sheep and calf origins-In Figure 14 are plotted the mean scores, and the standard errors of the means, for the Kiel and the Oswestry CXA's removed two, six and twelve weeks after implantation. The results are plotted separately for sheep and for calf bone.

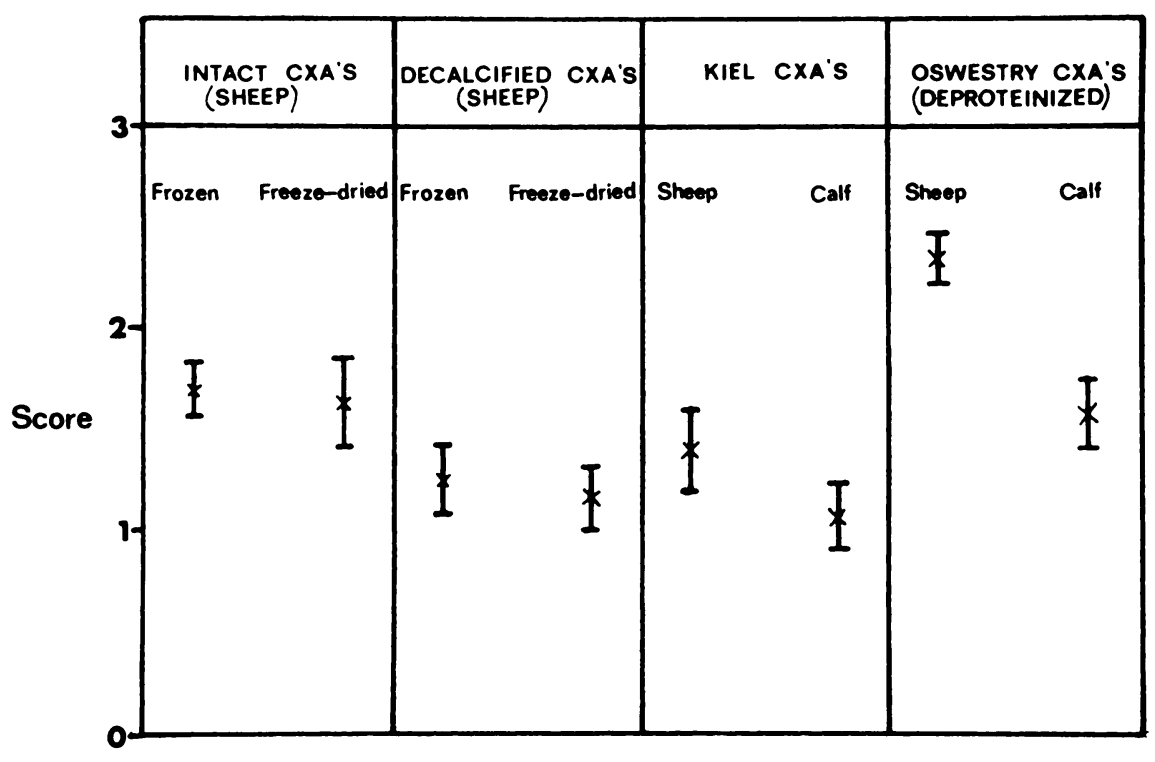

FIG. 15

The mean pooled scores summated at two, six and twelve weeks for composite grafts prepared with intact, decalcified, Kiel and Oswestry bone. The results are expressed as the means, and standard errors, of the score of new bone/grafted bone formed by all the grafts of each type of implant.

To consider first the sheep bone, the Oswestry CXA's formed significantly more new bone than all the Kiel CXA's at two weeks $(0.001<P<0.01)$ and again at six weeks $(\mathrm{P}<0.001)$, but not at twelve weeks. In the case of the calf bone, the Oswestry CXA's formed more new bone than did the Kiel CXA's only at six weeks $(\mathrm{P}<0.001)$.

Comparison of the pooled two, six and twelve weeks scores for each type of CXA-In Figure 15 the mean pooled scores of new bone to grafted bone for each type of CXA summated for two, six and twelve weeks are plotted. This was done in order to compare the pooled results from one type of CXA against the pooled results from any other. 


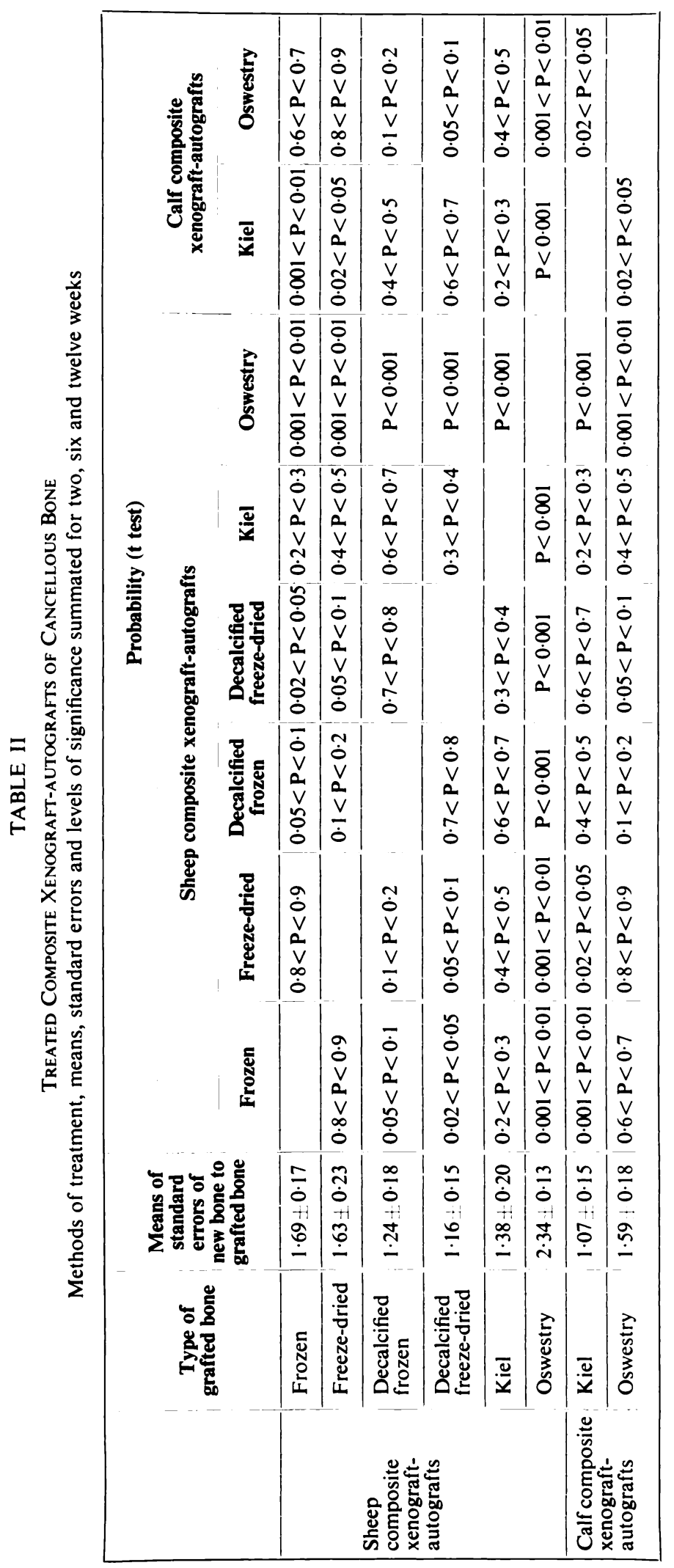

THE JOURNAL OF BONE AND JOINT SURGERY 

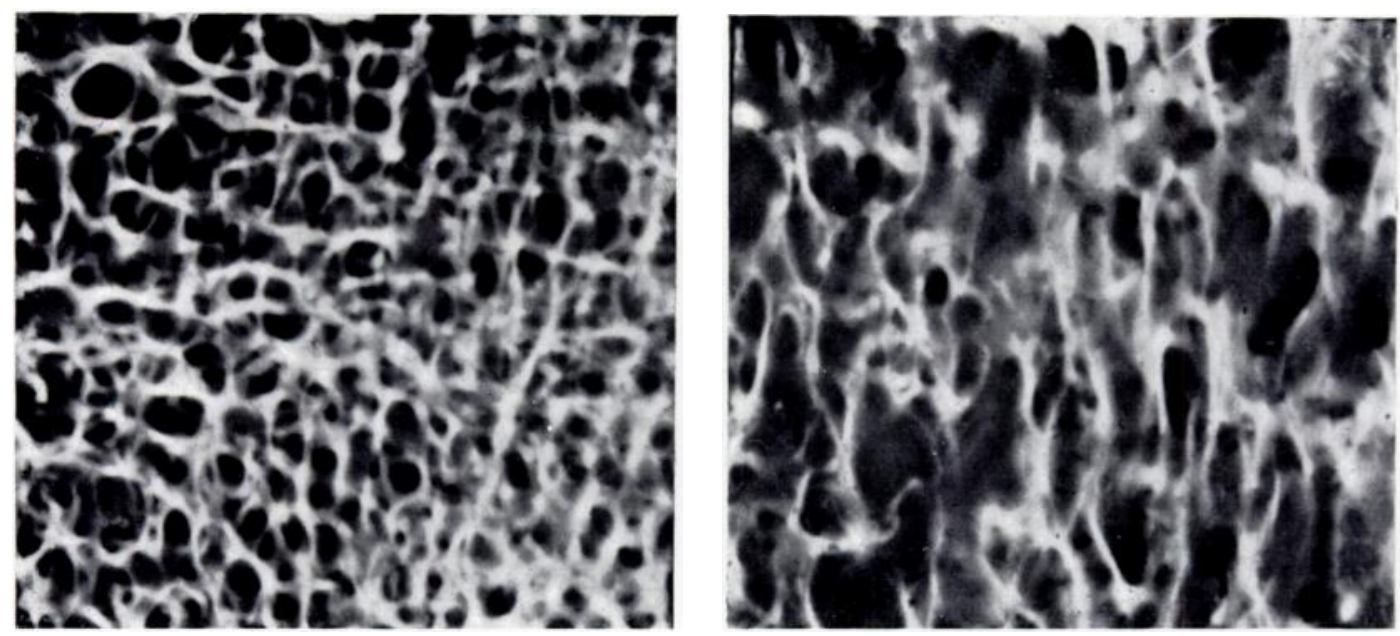

FIG. 16

Radiographs of calf and of sheep Kiel bone. Note the smaller size of the intertrabecular spaces in the calf bone (on the left). Similar appearances were evident in radiographs of calf and sheep bone prepared by freezing. freeze-drying and full deproteinisation.

The results of the statistical analysis (student's $t$ test), in which the mean pooled scores for each type of composite graft were compared, are shown in Table II.

Intact $C X A A^{\circ}$-There was no significant difference between the new bone formed by frozen and that formed by freeze-dried CXA`s. The mean pooled scores are similar: $1 \cdot 63 \pm 0 \cdot 23$ and $1 \cdot 69 \pm 0 \cdot 17$.

Decalcified $C X A$ s - The mean pooled score for the decalcified frozen CXA's $(1 \cdot 24 \pm 0 \cdot 18)$ was closely similar to that for the decalcified freeze-dried CXA's $(1 \cdot 16 \pm 0 \cdot 15)$.

Sheep Kiel and Oswestry $C X A$ 's - The mean pooled score for the Oswestry CXA's $(2 \cdot 34 \pm 0 \cdot 13)$ was very significantly greater than that for the Kiel CXA's $(1 \cdot 38 \pm 0.20)(\mathrm{P}<0.001)$.

Calf Kiel and Oswestry $C X A^{\prime} s-$ The mean pooled score for the Oswestry CXA's $(1 \cdot 59 \pm 0 \cdot 18)$ was significantly greater than that for the Kiel CXA`s $(1.07 \pm 0.15)(0.02<\mathrm{P}<0.05)$.

Sheep and calf donor bone compared-The sheep bone of Oswestry type as CXA's formed significantly more new bone than did the calf Oswestry bone as CXA's $(0.001<\mathbf{P}<0.01)$. But this was not so for the Kiel bone $(0 \cdot 2<\mathbf{P}<0 \cdot 3)$.

\section{RADIOLOGICAL OBSERVATIONS}

The intertrabecular spaces of the sheep bone used in the present study were much larger than those of the calf bone (Fig. 16).

\section{BIOCHEMICAL RESLLTS}

The results of the biochemical estimations on various types of donor bone used in the present study are shown in Table III.

Comparison of the mean pooled scores of new bone/grafted bone in various composite grafts and collagen of the donor bone-In Figure 17 is plotted $a$ ) the collagen expressed as a percentage for decalcified bone, freeze-dried bone and Oswestry bone, against $b$ ) the mean pooled scores for sheep CXA's prepared from similar examples of donor bone. There is the suggestion of an inverse relation between the score and the percentage of collagen.

\section{DISCUSSION}

The histological findings recorded in this paper showed a number of features relating to xenograft (heterograft) bank bone implanted heterotopically-firstly, that xenograft

VOL. 55 B, O. 2, MAY 1973 
cancellous bone which had been devitalised did not produce new bone after intramuscular implantation; secondly, that the impregnation of such foreign bone grafts with autologous red marrow as composite grafts added an osteogenic component in the form of the marrow; thirdly, that the amount of new bone formed depended upon the method of treatment of the foreign bone: in the case of the sheep CXA's, removing the mineral from the donor bone

TABLE III

Biochemical Estimations on Various Types of Donor Bone

\begin{tabular}{|c|c|c|c|c|c|}
\hline $\begin{array}{l}\text { Source of } \\
\text { donor bone }\end{array}$ & Type of bone & $\begin{array}{c}\text { Collagen } \\
\text { (per cent) }\end{array}$ & $\begin{array}{l}\text { Hexuronic } \\
\text { acid } \\
\text { (per cent) }\end{array}$ & $\begin{array}{c}\text { Calcium } \\
\text { (per cent) }\end{array}$ & $\begin{array}{c}\text { Mineral } \\
\text { (per cent) }\end{array}$ \\
\hline \multirow{3}{*}{ Sheep } & Freeze-dried & $19 \cdot 2$ & 0.06 & $20 \cdot 3$ & $49 \cdot 4$ \\
\hline & $\begin{array}{l}\text { Decalcified } \\
\text { freeze-dried }\end{array}$ & $81 \cdot 5$ & $0 \cdot 17$ & $0 \cdot 4$ & $1 \cdot 0$ \\
\hline & Kiel & $16 \cdot 0$ & 0.05 & $26 \cdot 6$ & $64 \cdot 5$ \\
\hline \multirow{2}{*}{ Calf } & Kiel & $19 \cdot 9$ & 0.05 & $27 \cdot 0$ & $65 \cdot 5$ \\
\hline & Oswestry & 0.00 & 0.00 & $36 \cdot 4$ & $88 \cdot 2$ \\
\hline
\end{tabular}

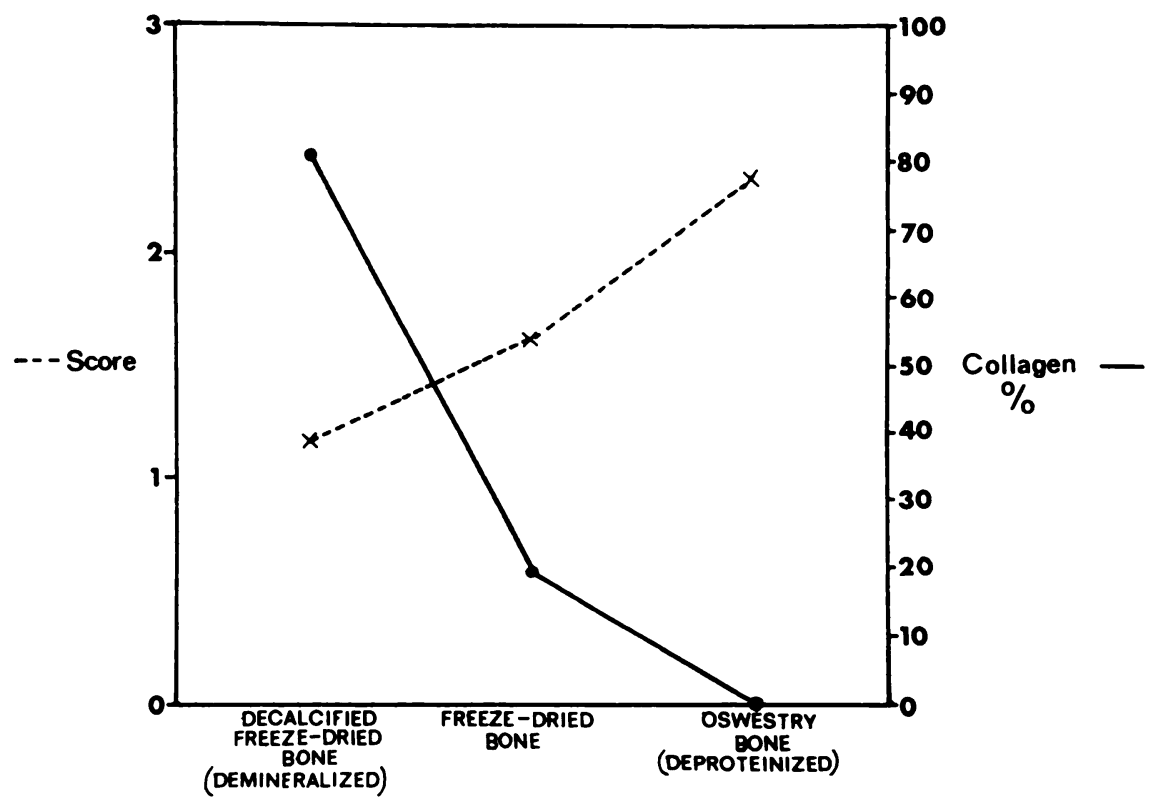

FIG. 17

Graph to show the mean pooled scores for composite grafts prepared from decalcified freeze-dried, freeze-dried and Oswestry sheep bone plotted against the collagen content of similar samples of donor bone expressed as percentages.

may have reduced new bone formation, whereas removing the organic material increased osteogenesis; and fourthly, that fully deproteinised bone prepared from the ilium of the sheep provided a better environment for osteogenesis by autologous marrow than did calf iliac bone similarly prepared.

The origin of the bone formed in the composite grafts--Only one of the devitalised xenografts implanted without autologous red marrow formed new bone. Hence it seems justified to attribute the new bone formed by the CXA's to their marrow content. 
The facilitating effect of xenograft cancellous bone upon osteogenesis by marrow: the argument for the absence of an osteogenic inductive effect by xenograft bone in composite grafts- In attempting to assess any facilitating effect of xenograft bone upon osteogenesis by marrow, it is necessary to know first the fate of marrow autografts transplanted alone. Because of the absence in the present study of any information relating to marrow autografts transplanted alone, recourse must be made to a previous report of bone formation in $\mathbf{4 3}$ per cent of marrow autografts transplanted into Wistar rats (Burwell 1964).

In the present work new bone formation was found in all but seven of 223 composite grafts. This suggests that the xenograft bone did in some way facilitate osteogenesis in the red marrow. Three mechanisms are possible: $a$ ) by keeping the marrow as a discrete mass, leading to a more extensive necrosis within it and, through the hypothesis of medullary intrinsic induction (Burwell 1966), to a greater osteogenic inductive effect; $b$ ) by protecting the soft marrow from the squeezing action of skeletal muscles and so maintaining more marrow cells at the site of implantation; and $c$ ) by the devitalised bone tissue itself exerting an extrinsic inductive effect upon the marrow cells. Now the evidence from the previous study of composite allograft-autografts (Burwell 1966) led to the conclusion that deproteinised (anorganic) allograft bone does not possess any inductive property towards red marrow. Hence it is likely that this property is also absent from deproteinised (Oswestry) xenograft bone.

If, then, mechanisms $(a)$ and $(b)$ rather than $(c)$ operated in the Oswestry CXA's, the same mechanisms may also have been responsible for the almost ubiquitous new bone formation in the other types of sheep CXA's. Hence it is concluded that the present experiments do not provide any evidence for an osteogenic inductive effect by xenograft cancellous bone upon autologous marrow in CXA's.

How does the physico-chemical treatment of xenograft bone influence new bone formation by marrow cells transplanted with it? The argument that the organic material of xenograft bone exerts an inhibitory effect upon osteogenesis by marrow in composite grafts-In discussing how osteogenesis in marrow autografts may be influenced by its bony micro-environment. it is possible here to compare only the new bone formed by one type of CXA with that produced by another CXA.

To consider the effect of removing the organic material from sheep donor bone, the mean pooled scores for the deproteinised (Oswestry) CXA's was significantly greater than that of any other type of CXA-intact, decalcified and Kiel (Fig. 15, Table II). A hypothesis to explain this difference is that the organic component of intact, decalcified and Kiel xenograft bone in CXA's, by exciting an immune response, causes more marrow cells to be deviated towards a local immune reaction and away from osteogenesis. Hence, if the organic material is fully removed from a xenograft, as it is in Oswestry bone, the marrow cells can proceed unimpeded to osteogenesis. The hypothesis also accounts for how the calf deproteinised (Oswestry) CXA's formed more new bone than did the calf Kiel CXA's (Fig. 15).

The presence of collections of mature plasma cells in bone xenografts not deproteinised and implanted alone; are such grafts micro-organs of antibody formation?-It is unknown whether the mature plasma cells observed in the protein-containing bone xenografts were formed locally or came from the surrounding tissues. In any event their presence can reasonably be taken as indicating the immunogenicity of such grafts. The less marked infiltrations with mature cells in the Kiel and Oswestry bone xenografts provide some evidence that such grafts are less immunogenic than intact or simply decalcified bone xenografts. Moreover, it supports the view that the immunogenicity of bone xenografts lies within its organic material.

In general, then, it seems that not only are intact and decalcified bone xenografts immunogenic, but that these implants rapidly acquire a population of cells belonging to the series that produces humoral antibodies. Such grafts may then become peripheral microorgans of humoral antibody formation.

The difference between composite grafts prepared from sheep and from calf bone; a role of

vol. 55 B, NO. 2, MAY 1973 
physical factors in osteogenic induction?-The composite grafts using sheep bone prepared at Oswestry formed significantly more new bone than those based on calf donor bone prepared in the same way (Fig. 15, Table II). The reason for this difference is not clear. One possibility is that the sheep bone provided a better physical environment for osteogenesis by marrow cells than did the calf bone. It is noteworthy that the intertrabecular spaces of the iliac bone taken from old sheep were larger than those of similar bone taken from a young calf (Fig. 16).

In this connection it has recently been shown (Winter and Simpson 1969, Winter 1970, 1971) that important factors in the induction of new bone by a plastic sponge implanted hypodermically into pigs are : $a$ ) the chemical nature of the sponge trabeculae, which are hydrophilic due to numerous reactive hydroxyl radicals; $b$ ) the deposition of calcium salts upon the surfaces of these trabeculae after implantation; and $c$ ) the dimensions of the intercommunicating pores of the sponge.

Clearly, the relation to osteogenesis of the dimensions of the intertrabecular spaces ("communicating tunnels") in fully deproteinised composite allograft-autografts and in composite xenograft-autografts taken from different species, and from animals of different ages, needs greater appraisal.

\section{SUMMARY}

1. This paper reports a histological study of the fate of sheep and calf cancellous bone grafts impregnated with autologous red marrow of Wistar rats and implanted intramuscularly as composite xenograft-autografts for two to twelve weeks. It also includes some biochemical estimations of certain types of sheep and calf bone used to prepare these composite grafts.

2. Only one of 223 devitalised bone xenografts implanted without autologous marrow formed new bone: in contrast 216 of 223 transplanted with marrow formed new bone.

3. The new bone formed by the composite grafts is derived from the autologous marrow. There was no evidence for an inductive effect upon the marrow of the various types of xenograft bone studied as described previously for allograft bone (Burwell 1966).

4. The highest score of new bone formation was found in composite grafts based on fully deproteinised sheep iliac bone prepared at Oswestry. Statistically this score was significantly higher than those registered by composite grafts prepared from intact (frozen and freeze-dried), decalcified (frozen and freeze-dried) and Kiel sheep bone, and by Kiel and Oswestry calf bone (Table II).

5. The histological evidence reported suggests that the high score with the sheep Oswestry composite grafts is because Oswestry bone is feebly immunogenic, if at all; and that such feeble or absent immunogenicity permits more marrow cells to differentiate into osteoblasts and lay down new bone without impediment.

6. The lower scores of new bone formation in most of the undeproteinised composite grafts of sheep origin-intact frozen, intact freeze-dried and Kiel-are attributed to residual immunogenicity within the organic material of the donor bone, because each type evoked the formation of mature plasma cells.

7. The Kiel bone grafts appeared to evoke less of a plasma cell reaction and may be less immunogenic than the intact and decalcified bone xenografts.

8. The sheep Oswestry CXA's formed significantly more new bone than did the calf Oswestry CXA's. This difference may be due to the different physical properties of the bone obtained from old sheep compared with the bone obtained from a young calf.

\section{ADDENDUM}

Since this paper was submitted for publication, the findings of Hollmann et al. (1971) relating to composite grafts of calf Kiel bone and autologous red marrow have been published more fully (Plenk, Hollmann and Wilfert 1972). 
The writers are greatly indebted to the National Fund for Research into Crippling Diseases for financial support. We are also grateful to Professor H. A. Sissons for the radiographs of the bone specimens; to Messrs B. Braun of Melsungen, West Germany, for preparing the Kiel bone; and to Mr R. Kershaw, M.P.S., Chief Pharmacist to the Robert Jones and Agnes Hunt Orthopaedic Hospital, for preparing the Oswestry bone.

\section{REFERENCES}

ANtonopoulos, C. A., Gardell, S., Szirmai, J. A., and De Tyssonsk, E. R. (1964): Determination of Glycosaminoglycans (Mucopolysaccharides) from Tissues on the Microgram Scale. Biochimica et Biophysica acta, 83, 1.

Bitter, T., and Muir, H. M. (1962): A Modified Uronic Acid Carbazole Reaction. Analytical Biochemistry; 4, 330.

Boyne, P. J. (1970): Autogenous Cancellous Bone and Marrow Transplants. Clinical Orthopaedics and Related Research, 73, 199.

Burwell, R. G. (1964): Studies in the Transplantation of Bone. VII. The Fresh Composite HomograftAutograft of Cancellous Bone. An Analysis of Factors Leading to Osteogenesis in Marrow Transplants and in Marrow-containing Bone Grafts. Journal of Bone and Joint Surgery, 46-B, 110.

Burwell, R. G. (1966): Studies in the Transplantation of Bone. VIII. Treated Composite Homograftautografts of Cancellous Bone: an Analysis of Inductive Mechanisms in Bone Transplantation. Journal of Bone and Joint Surgery, 48-B, 532.

EAstoe, J. E. (1955): The Amino Acid Composition of Mammalian Collagen and Gelatin. Biochemical Journal, 61, 589.

Elves, M. W. (1970): Fluorochromatic Cytotoxic Test. In “Manual of Tissue Typing Techniques”, p. 24. Edited by D. L. Brand and J. G. Ray, Jun. Bethesda, Maryland: National Institutes of Health.

Elves, M. W., and Salama, R. (1973): Immunological Studies of Xenografts (Heterografts) of Iliac Bone Using a Fluorochromatic Method to Detect Serum Cytotoxic Antibodies. In preparation.

Hollmann, K., Plenk, H., Jun., and Wilfert, K. H. (1971): Die Vitalisierung des Kieler-Knockenspanes mit autologem Knockenmark im Tierversuch. Wiener klinische Wochenschrift, 83, 301.

Kershaw, R. (1963): Preparation of Anorganic Bone Grafting Material. Pharmaceutical Journal, 190, 537.

Matthes, T. von, Gibel, W., Wildner, G., and MarX, G. (1968): Experimentelle Untersuchungen zur Möglichkeit einer Rekonstruktion der Thoraxwand mit homologen Rippen nach dem Prinzip des Kieler Knockenspans bei gleichzeitiger Spongiosa. Zeitschrift für experimentelle Chirurgie und chirurgische Forschung, 1, 360.

Nade, S. M. (1969): Personal communication.

NADE, S. (1970): Bone-Graft Surgery Reappraised: the Contribution of the Cell to Ultimate Success. British Journal of Surgery, 57, 752.

Plenk, H., Jun., HollmanN, K., and Wilfert, K.-H. (1972): Experimental Bridging of Osseous Defects in Rats by the Implantation of Kiel Bone Containing Fresh Autologous Marrow. Journal of Bune and Joint Surgery, 54-B, 735.

SAYERS, D. C. J. (1972): Unpublished method.

WINTER, G. (1970): Heterotopic Bone Formation in a Synthetic Sponge. Proceedings of the Royal Society of Medicine, 63, 1111.

WINTER, G. D. (1971): Calcification and Ossification Induced Experimentally. Proceedings of the Royal Society' of Medicine, 64, 645.

Winter, G., and Simpson, B. J. (1969): Heterotopic Bone Formed in a Synthetic Sponge in the Skin of Young Pigs. Nature, London, 223, 88.

WOESSNER, J. F., Jun. (1961): The Determination of Hydroxyproline in Tissue and Protein Samples Containing Small Proportions of this Imino Acid. Archives of Biochemistry and Biophysics, 93, 440. 